https://helda.helsinki.fi

\title{
Knowing Without Having The Competence to Do So
}

\section{Hirvelä, Jaakko}

2019-06

Hirvelä , J 2019 , ' Knowing Without Having The Competence to Do So ' , Thought: A Journal of Philosophy , vol. 8 , no. 2 , pp. 110-118 . https://doi.org/10.1002/tht3.411

http://hdl.handle.net/10138/307502

https://doi.org/10.1002/tht3.411

acceptedVersion

Downloaded from Helda, University of Helsinki institutional repository.

This is an electronic reprint of the original article.

This reprint may differ from the original in pagination and typographic detail.

Please cite the original version. 


\title{
KNOWING WITHOUT HAVING THE COMPETENCE TO DO SO
}

\begin{abstract}
According to all varieties of virtue reliabilism knowledge is always gained through the exercise of epistemic competences. These competences can be conceived as competences to form true beliefs, or as competences to know. I will present a short but decisive argument against the idea that knowledge is always gained through the exercise of competences to know. The competence to know isn't necessary for gaining knowledge.
\end{abstract}

According to virtue reliabilism knowledge is a type of performance that is the exercise of the subject's epistemic competences. Being a performance, knowledge can be evaluated as performances in general are evaluated. Sosa's (2007, pp. 22-23) AAA-model for performance normativity is the standard one. According to the AAA-model all goal oriented performances can be evaluated on three aspects: accuracy, adroitness and aptness. A performance is accurate if it achieves its aim, adroit if it manifests the subject's relevant competence and apt if the performance is accurate because adroit. Virtue reliabilists come in two varieties when it comes to filling out the details of this schema. Traditional, indirect, virtue reliabilists hold that a belief is accurate if true and that the competences relevant for knowledge are competences to believe truly. ${ }^{1}$ Knowledge first, or direct, virtue reliabilists, championed by Miracchi (2015) and Kelp (2017), claim that success in the realm of belief is to be conceived as knowledge and that the competences relevant for knowledge are competences to know. ${ }^{2}$ I will present an argument against direct virtue reliabilism by demonstrating that competences to know are not necessary for knowledge. The reason why

\footnotetext{
${ }^{1}$ Proponents of indirect virtue reliabilism include Sosa (2007, 2015), Greco (2010) and Turri (2011) to name a few.

${ }^{2}$ I borrow the terms indirect and direct virtue reliabilism from Miracchi (2015).
} 
competences to know are not necessary for knowledge is because it applies to all goal oriented performances that one can succeed in attaining the relevant goal without having the competence to do so. My aim isn't so much to demonstrate that Miracchi's and Kelp's views per se are false. Rather, it's to demonstrate that the central idea that is shared by direct virtue reliabilists is untenable: the competence to know isn't necessary for knowledge. I should also emphasize that even though the central argument of this paper is applicable only to direct virtue reliabilism this isn't a defense of indirect virtue reliabilism. I endorse neither direct nor indirect virtue reliabilism, but my reasons for rejecting the latter view are orthogonal to this paper. ${ }^{3}$

It's certainly possible to succeed in one's endeavors without having the relevant competence (Kenny, 1976). For example, it's possible that I pocket all of the striped balls in eight-ball with a single shot without having the competence to do so. If I had such a competence I would succeed in the task with a sufficient success-rate while in appropriate conditions. Of course the required success-rate in such a hard task would not be anywhere near 50\%, but it would have to be significantly higher than the success-rate of someone who lacked the competence.

It's also clear that if one succeeds in $\varphi$-ing one was able to $\varphi$. Note how awkward it would be to deny this. Suppose that I succeed in pocketing all of the striped balls with one shot. The assertion "Well, he pocketed all of the striped balls with a single shot but he was not able to do it" is clearly infelicitous. Success in $\varphi$-ing entails that one was able to $\varphi$, but it doesn't entail that one has the competence to $\varphi$. After all, the assertion "Well, he pocketed all of the striped balls with a single shot but he nevertheless doesn't have such a competence" is perfectly appropriate. What then is the relationship between being able to $\varphi$ and having the competence to $\varphi$ ?

To be able to $\varphi$ entails that it's possible that one succeeds in $\varphi$-ing. Note that being able to $\varphi$ doesn't even entail that it's possible that one could have the competence to $\varphi$. It's

${ }^{3}$ See my (2018, forthcoming). 
metaphysically possible that one is able to $\varphi$ without it being metaphysically possible that one has the competence to $\varphi$. Casting six sixes in a row in a fair way with a fair dice is something that one is able to do, but having the competence to do that is impossible.

Having the competence to $\varphi$ requires much more than being able to $\varphi$. It requires that one has a high rate of success in $\varphi$-ing whenever one attempts to $\varphi$ in circumstances that are suitable for $\varphi$-ing. What counts as high rate of success varies from goal oriented performance to another. One might count as having the competence to hit fastballs in baseball even though one's success rate is well below $50 \%$. In the case of epistemic competences the success-rate has to be well above $50 \%$. If my perceptual "competences" led me to a false belief half of the time, we could hardly say that my perceptual capacities constituted a competence. Moreover, we should bear in mind that actual track-records do not matter when assessing whether someone has the competence to $\varphi$. One might have an outstanding competence to $\varphi$ and yet never succeed in $\varphi$-ing because of incredibly bad luck. What matters is that one has a high rate of success in $\varphi$-ing across relevantly close nearby possible worlds where one attempts to $\varphi($ Greco, 2010, p. 77).

Competences are often understood as dispositions to succeed. According to Sosa (2007, p. 29) a competence "is a disposition, one with a basis resident in the competent agent, one that would in appropriately normal conditions ensure (or make highly likely) the success of any relevant performance issued by it". ${ }^{4}$ While competences are perhaps most naturally understood as dispositions to succeed, there are other options. Lisa Miracchi (2014, pp. 4446), for instance takes competences to be a sui generis property that only subjects (in virtue of having cognitive systems) can have, which allow the subject to reliably attain success when exercising the competence in question. ${ }^{5}$ For our purposes these subtle differences do

\footnotetext{
${ }^{4}$ Virtue epistemologists who conceive competences as dispositions to succeed include Greco (2010), Pritchard (2012) and Littlejohn (2014) among others.

${ }^{5}$ See Riley (2017) for critique of defining skills in terms of dispositions. Vetter (2016) and Vetter and Jaster (2017) argue that the dispositional account of competences invoked by virtue reliabilists does
} 
not matter. What is crucial is that a subject has a competence to $\varphi$ only if the subject would succeed in $\varphi$-ing (at least partially in virtue of her intrinsic properties) if she attempted to $\varphi$ in circumstances suitable for $\varphi$-ing with a sufficient degree of reliability.

Finally, it's worth noting that a competence can be merely exercised or manifested. A master archer exercises her competence in archery when she fires a shot, but that shot hitting the target doesn't manifest the archer's competence unless it hit the target because the shot was competent. If the arrow was diverted of track by a powerful gust of wind, but guided back on track due to another gust, the fact that the arrow hit the target would not manifest the archer's competence, even though she exercised her competence in shooting the arrow.

With these distinctions in place, let's return to direct virtue reliabilism. According to direct virtue reliabilism, knowledge is always gained through an exercise of competence to know. On Miracchi's (2015, p. 48) view knowledge just is an (non-degenerate) exercise of a competence to know. ${ }^{6}$ On Kelp's (2017) view knowledge is an apt belief, where apt belief is defined partially in terms of competences to know. On both accounts knowledge is always gained through a competence to know.

not give a general account of competences since abilities and dispositions have a different modal structure. The argument advanced here does not presuppose that competences could be defined in terms of dispositions.

${ }^{6}$ In addition Miracchi $(2015$, p. 42) holds that knowledge is a mental state. While the idea that knowledge is a mental state is a central feature of her view, it's orthogonal to the argument that is advanced here. Firstly, nothing I say is incompatible with the idea that knowledge is a mental state. Secondly, if my argument is sound, one could be in a mental state without having the competence to be in that state, since it would apply for all goal oriented performances that one can succeed in attaining the goal in question without having the competence to attain that goal. If my argument is sound it will also serve as a counterargument against the particular way in which Miracchi (2017) develops her perception-first account of perceptual states. I would like to thank an anonymous referee for making me consider this issue. 
If the above remarks are correct it should be easy to see that the competence to know isn't necessary for knowledge. After all, it's true of all goal oriented performances that one can succeed in attaining the goal in question without having the competence to do so. Therefore a performance can be accurate without being adroit since one might lack the relevant competence. This is something that Sosa (2007, p. 78), for example, readily accepts. But if this is true then one can know that $p$ without having the competence to know that $p$.

Kelp foresees this objection and argues that there is a subset of goal oriented performances which are such that one cannot attain the relevant goal unless one did so competently. Furthermore, he claims that knowledge belongs to this special category of goal oriented performances. Miracchi assumes that knowledge is an achievement that is to be explained by the knower's competence and argues that indirect virtue reliabilists cannot explain what kind of state knowledge is, since there is no general relation between an exercise of a competence to believe truly and believing truly that is constitutive of knowledge. She does this by presenting two cases of ignorance where the subjects are systematically Gettiered and yet seem to satisfy the conditions for knowledge put forth by indirect virtue reliabilists. She argues that if the competences relevant for knowledge are understood as competences to know, then these thought experiments can be dealt with, and we can explain how knowledge is an achievement. Hence, knowledge cannot be understood separately from the competence to know (Miracchi, 2015, pp. 40-42). However, on closer inspection it turns out that indirect virtue reliabilists do have the resources to deal with both of Miracchi's thought experiments, and therefore Miracchi's argument fails.

In the first case offered by Miracchi (2015, p. 33), the subject believes that there is a sheep in the field on the basis of seeing a sheepdog, which (unbeknownst to the subject) would not have been there unless there was a sheep in the field. Sosa's conditions for perceptual knowledge are not satisfied in this case. After all, Sosa (2011, pp. 55-56) explicitly requires that in cases of perceptual knowledge the subject's apt belief must be based on an apt perceptual experience, and it's clear that the subject's perceptual belief isn't based on an apt 
perceptual experience in the above case, since the subject's perceptual experience represents the sheepdog as a sheep. In the second case the subject forms a belief by receiving testimony from someone who is trying to lie to him but ends up telling the truth since she has been lied to by a third party, and the lies cancel each other out (Miracchi, 2015, p. 39). Sosa's conditions for testimonial knowledge are not satisfied in this case, since Sosa claims that in cases of testimonial knowledge both the testifier and the receiver of the testimony have to be competent (2007, pp. 95-96; 2011, p. 87). It's their joint competence that is manifested in the apt belief of the subject in cases of testimonial knowledge. Since the testifiers in the above case are attempting to convey what is false it ought to be clear that they are not testifying competently, and hence the recipient of the testimony doesn't know, as required. ${ }^{7}$

Let's now consider Kelp's argument that certain goal-oriented performances are such that one can succeed in attaining the relevant goal only if one has the competence to attain that goal.

According to Kelp one cannot succeed in joining consenting adults in lawful marriage without competently conducting a marital ceremony. He writes:

Crucially, there is reason to believe that one joins partners in a lawful marriage only if one competently conducts a token of $c$. To see this, suppose that you, the master of ceremony, fail to competently conduct a token of $c$. This may be for two reasons. You may fail to conduct a token of $c$ altogether, say because you are too drunk and so do not manage to say enough of the relevant words. Or else the [simple goal-directed practice] may not be within the range of $c$, say because one of the partners is underage and so a different

\footnotetext{
${ }^{7}$ That said, the issue whether Sosa is able to deal with Miracchi's counterexamples is orthogonal for the argument advanced here, since my argument doesn't presuppose that knowledge is an achievement. I would like to thank an anonymous referee at Thought for encouraging me to engage with Miracchi's argument in greater detail.
} 
kind of ceremony is needed. In either case, the couple will not end up lawfully married. (2017, p. 237)

But why should we think that you can fail to competently conduct a token of $c$ only for the kind of reasons that Kelp mentions? According to Kelp, the competence to $\varphi$ requires that one has a disposition to succeed to $\varphi$ via 'way of move production', while in suitable circumstances. A way of move production is a way in which the competence can be exercised. One has competence to $\varphi$ just in case there is a way of move production, and using that way of move production in suitable conditions disposes one to succeed in $\varphi$-ing. (Kelp, 2017, p. 234) For example, I might have the competence to hit the target in archery when shooting with my left hand, but not when shooting with my right hand (Kelp, 2017, p. 233). Someone who lacks a competence to $\varphi$ cannot competently $\varphi$. Clearly, however, one can lawfully marry a couple even if one lacks the disposition to succeed in marrying couples when one attempts to do so in circumstances suitable for lawful marrying. Suppose that the master of the ceremony has a disposition to forget some of the words that are necessary for a token of $c$, but nevertheless manages to say all the right words when you and your partner are the altar. Assuming that the master of the ceremony has the institutional right to join consenting couples in lawful marriage, and that you are suitable targets for the ceremony, there is no reason to think that you are not lawfully married at the end of the ceremony. However, given that the master of the ceremony has a disposition to fail to conduct a token of $c$, she cannot have the competence to conduct tokens of $c$. Therefore one can lawfully marry a couple even if one lacks the competence to do so. Note that the relevant sort of competence here is a disposition (or a propensity) to succeed in joining consenting couples in lawful marriage - not the institutional competence or power that is granted by the state. Crucially, having the institutional power to conduct a marital ceremony doesn't entail that one would have a disposition to succeed in conducting such a ceremony when one tried.

It could be argued on behalf of Kelp that the relevant way of move production at issue in lawful marrying is to completely carry out the token $c$, and that the master of ceremony in 
the above case is disposed to succeed in lawfully marrying when she manages to carry out $c$ properly. Hence, the master of the ceremony would exercise the competence to lawfully marry when she succeeds in lawfully marrying a couple. ${ }^{8}$

There are two reasons why this move doesn't help Kelp. Firstly, there are principled reasons to think that ways of move production shouldn't be individuated in such a fine-grained manner. If the way of move production in archery was defined as [shooting from 'this distance' with the bow being drawn with 'this many pounds', while the angle of the arrow to the target was 'this many degrees'] then anyone would have the competence to hit the target. But clearly this isn't the kind of competence we are interested in when we are talking about competence in archery. Rather, when we say that someone is a competent archer, we mean that she would hit the target via the way of move production that she usually employs. ${ }^{9}$ Kelp does seem to recognize this, since when it comes to competence in archery the way of move production that he mentions is shooting with one's left or right arm (2017, p. 233). This is of course much more coarse-grained. It would be highly ad hoc if the way of move production should be understood very fine-grainedly when it comes to lawful marrying, but very coarsegrainedly when it comes to archery.

Secondly, the case could be altered so that the master of the ceremony conducts token $c$ perfectly in suitable conditions for lawful marrying, but nevertheless lacks the disposition to succeed in lawfully marrying couples via conducting $c$ in suitable conditions for lawful marrying. Suppose, for instance, that the marriage law is about to change and in most possible worlds it has already changed. As a result, the ceremony that must be conducted when lawfully marrying a couple will also change. The master of ceremony is, however, unaware of these changes and would use the old ceremony even if the new law was in force. If you and your partner are married by the oblivious master of the ceremony just moments before the new law enters into force there is no reason to think that you are not lawfully

\footnotetext{
${ }^{8}$ I would like to thank another anonymous referee of Thought for raising this objection.

${ }^{9}$ Vetter (2016, p. 15) argues also that an account of abilities which entailed that everyone would have those abilities is absurd.
} 
married at the end of the ceremony. However, it's equally clear that the master of the ceremony isn't disposed to succeed in lawfully marrying couples via conducting $c$, while in suitable conditions for lawful marriage. Since she isn't so disposed, she doesn't have the competence to lawfully marry. Finally, note that the fact that the marriage law is about to change doesn't make the conditions for lawful marriage unfavorable. It's perfectly possible to marry couples even though the law is about to change.

Kelp claims that other plausible candidates of performances in which success entails competence are certain types of intentional action, such as winking, waving and applauding. However, the above argument can easily be adapted to these cases. Take winking for example. To successfully wink is to close one eye for a short period of time intentionally as a way of greeting someone, showing that you are not serious, etc. One can succeed in doing this without having the disposition to succeed to wink when one attempts to wink in circumstances suitable for winking. Many people end up blinking their left eye when they attempt to wink with their right eye, and thereby fail to wink. The fact that they fail more often than succeed, doesn't mean that they would not wink when they manage to hold their left eye open.

Given that the best examples of performances in which success supposedly entails competence fail, it's plausible to think that there are no goal oriented performances for which it's true that the attaining of the goal entails that it was attained via a competence. Kelp's reasoning for rejecting our argument fails. Direct virtue reliabilists must give us convincing reasons to think that there are some goal oriented practices in which one can succeed only if one has the competence to succeed in that practice. In the absence of such arguments we should be highly suspicious of direct virtue reliabilism.

At this point one might wonder whether there are any actual cases where one lacks the competence to know that $p$, but nevertheless intuitively knows that $p$. Perhaps the following case might be a good candidate. Suppose that $\mathrm{S}$ conducts a very long and hard single multipremise deduction from premises that she knows to a true conclusion. Given that knowledge 
is preserved in deductive inferences $\mathrm{S}$ ought to know the conclusion. Assuming that the deductive inference is very hard and long $\mathrm{S}$ will in most nearby possible worlds fail at some point in the deduction. Therefore she doesn't have a disposition (or a propensity) to succeed in the extremely complex deduction that she undertakes, and hence her belief isn't gained through a competence to know, because in most nearby possible worlds she will end up with a false belief, and a fortiori not knowledge. Given that the subject lacks the competence to know and yet intuitively knows the conclusion, we have a counter example to direct virtue reliabilism.

Now one might worry that the conclusion isn't properly based on the premises unless the deduction is also competent, and argue that if the deduction is competent then it does manifest the subject's competence to know. ${ }^{10}$ To dismantle this worry we need to make a distinction between 'competent deduction' and 'competence in deduction'. A deduction is said to be competent when the deduction process is guided by the rules of logic. ${ }^{11}$ This is arguably what knowledge through the deduction must require. 'Competence in deduction' requires that one is a competent deducer, that is, it requires that one is reliably enough guided in one's deduction attempts by the rules of logic. This is what direct virtue reliabilism would require for knowledge through deduction. However, since one can clearly be guided by the rules of logic on a particular occasion without being disposed to be guided by the rules of logic in general, it's possible to deduce a conclusion from known premises in such a

${ }^{10}$ I would like to thank yet another anonymous referee of Thought for raising this objection.

${ }^{11}$ Certainly, the use of the word 'competent' differs here from the way in which virtue epistemologists use the term to ascribe positive properties to agents. A deduction process that is guided by the laws of logic is competent in the sense that it's the right or proper way to conduct deductive inferences. More generally, competent actions need not arise from competence; it might be enough that the action is the right kind of response to the situation and is done for the right reasons (Lasonen-Aarnio, forthcoming). The same point applies to morally virtuous action. Virtuous acts need not arise from a virtuous character, it suffices that the action has the right kind of motivation (Hurka, 2006). Special thanks to Maria Lasonen-Aarnio for helpful discussion. 
way that the conclusion is properly based on the premises, without having the competence to deduce the conclusion. Those who think that knowledge is preserved under deductive inferences have good reasons to reject direct virtue reliabilism. ${ }^{12}$

Another set of cases of knowledge without competence to know are cases of misleading defeat where the subject stubbornly sticks to her belief. Lasonen-Aarnio (2010) has argued that misleading defeaters need not undermine one's knowledge, but do undermine the reasonableness of one's belief. She writes: "Reasonableness is at least largely a matter of managing one's beliefs through the adoption of policies that are generally knowledge conducive, thereby manifesting dispositions to know and avoid false belief across a wide range of normal cases" (2010, p. 2). It should be clear that an unreasonable belief will not be the manifestation of a competence to know, since unreasonable beliefs will be maintained by policies that have a disposition to lead to ignorance. If there is unreasonable knowledge then there clearly ought to be cases of knowledge where the subject lacks the competence to know.

It's worth noting that indirect virtue reliabilism, according to which the competences relevant for knowledge are competences to believe truly, rather than competences to know, doesn't straight forwardly fall prey to the kind of argument advanced here. After all, the proponents of indirect virtue reliabilism acknowledge that it's possible to believe the truth without doing so competently. Thus it seems that we have some reason to prefer traditional indirect virtue reliabilism over direct virtue reliabilism. ${ }^{13}$

${ }^{12}$ Note that Kelp (2017, note 13) confines his knowledge first virtue epistemology to basic knowledge, and hence this example isn't a direct counterexample to his view. It would, however, be very odd if his theory of inferential knowledge didn't require that in order to know one must have the competence to know. Hence I think that the above example does undermine the spirit, if not the letter, of Kelp's view. I would like to thank the same referee I thanked in the previous footnote.

${ }^{13}$ I would like to thank Giada Fratantonio, Maria Hämeen-Anttila, Markus Lammenranta, Maria Lasonen-Aarnio, Sanna Mattila, Tuukka Tanninen and three anonymous referees of Thought for 


\section{REFERENCES:}

Greco, J. (2010). Achieving Knowledge: A Virtue Theoretic Account of Epistemic Normativity. Cambridge: Cambridge University Press.

Hirvelä, J. (2018). On Virtue, Credit and Safety. Grazer Philosophische Studien, 95(1), 98120.

Hirvelä, J. (forthcoming). No Safe Haven For The Virtuous. Episteme.

Hurka, T. (2006). Virtuous act, virtuous dispositions. Analysis, 66(289), 69-76. doi:doi:10.1111/j.1467-8284.2006.00591.x

Kelp, C. (2017). Knowledge First Virtue Epistemology. In A. Carter, E. Gordon, \& B. Jarvis (Eds.), Knowledge First: Approaches in Epistemology and Mind (pp. 224-245). Oxford: Oxford University Press.

Kenny, A. (1976). Human Abilities and Dynamic Modalities. In J. Manninen \& R. Tuomela (Eds.), Essays on Explanation and Understanding (pp. 209-232). Dodrecht: Reidel.

Lasonen-Aarnio, M. (2010). Unreasonable Knowledge. Philosophical Perspectives, 24(1), 121.

Lasonen-Aarnio, M. (forthcoming). Competent Failure and Victims of Deceit. In F. Dorsch \& J. Dutant (Eds.), The New Evil Demon Problem. Oxford: Oxford Univeristy Press.

Littlejohn, C. (2014). Fake Barns and False Dilemmas. Episteme-a Journal of Individual and Social Epistemology, 11(4), 369-389. doi:10.1017/epi.2014.24

Miracchi, L. (2014). Getting Things Done. (Ph.D. Thesis), Rutgers University,

Miracchi, L. (2015). Competence to Know. Philosophical Studies, 172, 29-56.

Miracchi, L. (2017). Perception First. Journal of Philosophy, 114(12), 629-677.

Pritchard, D. (2012). Anti-Luck Virtue Epistemology. Journal of Philosophy, 109(3), 247279.

Riley, E. (2017). What skill is not. Analysis, 77(2), 344-354. doi:10.1093/analys/anx059

Sosa, E. (2007). A Virtue Epistemology: Apt Belief and Reflective Knowledge: Volume I. Oxford: Oxford University Press.

Sosa, E. (2011). Knowing Full Well. Princeton: Princeton University Press.

Sosa, E. (2015). Judgment and Agency. Oxford: Oxford University Press.

Turri, J. (2011). Manifest Failure: The Gettier Problem Solved. Philosophers Imprint, 11(8), $1-11$.

Vetter, B. (2016). Are abilities dispositions? Synthese. doi:10.1007/s11229-016-1152-7

Vetter, B., \& Jaster, R. (2017). Dispositional accounts of abilities. Philosophy Compass, 12(8), e12432-n/a. doi:10.1111/phc3.12432

helpful comments and discussion. This project has received funding from the European Research Council (ERC) under the European Union's Horizon 2020 research and innovation programme under grant agreement No 758539 . 